\title{
Intervention groups for HIV-infected women: the need for additional services
}

\author{
Irma Eloff \\ Faculty of Education, University of Pretoria, South Africa \\ irma.eloff@up.ac.za
}

Brian Forsyth
Yale University

Michelle Finestone, Liesel Ebersöhn, Maretha Visser and Ronél Ferreira

University of Pretoria

\author{
Alex Boeving \\ Wake Forest University

\section{Kathleen Sikkema} \\ Duke University
}

The Kgolo Mmogo study is a randomised controlled intervention trial that examines the effectiveness of a group intervention to enhance resilience in HIV-infected South African mothers $(N=427)$ and their young children $(N=435)$. We describe here how the severity of psychological and social problems experienced by some of the study participants required referrals for other services and discuss the barriers encountered in facilitating such referrals. Over a 30-month period 54 mothers and 59 children were referred for additional support. For mothers, the most frequent reasons for referral related to domestic violence and problems within relationships, while for children the most common grounds for referral were the evaluation and treatment of behavioural problems and severe emotional disturbances, including depression. Eight children were referred for suspected abuse. Observations from the study demonstrate that current systems for referral are overloaded and that there is a paucity of specialised services available. Our experience suggests that participants may benefit from using the intervention as a first point of support and that psychosocial referrals should perhaps be delayed until functional advice is provided (within the group) on ways of accessing wider support effectively. The intervention may also benefit from the inclusion of an intervention team member who is specifically tasked to follow up on referrals. This includes follow-up for participants who were not included in the group intervention. Furthermore, we argue that socio-economic constraints, which often manifest as lack of mobility to access service delivery, can severely impact on the implementation of an intervention study in a developing context. This constraint is experienced in terms of limited access to experimental intervention groups and services from referrals.

Keywords: children affected by HIV and AIDS; health services; HIV and AIDS; HIV-positive women; intervention groups; referrals

Inequalities in service delivery in the health sector have been well documented (Castro-Leal, Dayton, Demery, \& Mehra, 2000). Studies show that those who need health services the most are the least likely to receive such services (Gwatkin, Bhuiya, \& Victora, 2004; Makinen, Waters, Rauch, Almagambetova, Bitran, Gilson, McIntyre, Pannarunothai, Prieto, Ubilla, \& Ram, 2000). Gwatkin et al. (2004) also refer to the "inverse care law" where health services are not distributed to those who need them most. Instead, more and higher quality services are provided to the wealthy (often less in need of health services) and fewer services are made available to the poor, who struggle to access them.

To some extent this gap widens even more when the need for additional referrals arises within the health sector. Studies on referrals within the health sector have found a link between perceived severity of the reason for referral and actual subsequent referral (Maniadaki, Sonuga-Barke, \& 
Kakouros, 2006). Thus, the more intense the problem experienced by a patient (or participant in the case of research), the more likely that he/she will be referred for additional health services. This means that those who need it most, will (probably) also be referred more often. If access to health care is already problematic for those who need it most (e.g. those affected by poverty), then further referrals may inadvertently magnify the existing problem. For instance, when the reason for referral is severe, the paucity of resources often acts as a further compounding factor. Yet, referrals are crucial to effective health care when patients present with multiple challenges. It is also crucial in a health care system where support is provided by a variety of health professionals. Covell, Essock, Felton, and Donahue (2006) conducted a study on traumatic stress and found that patients with a wider range of symptoms - covering the behavioural, cognitive, emotional and physical domains - were also in greater need of referrals.

We conducted psychosocial intervention groups with mothers and children affected by HIV and AIDS within the Kgolo Mmogo research project for the last five years. The assumption that directed the randomised trial, measurement of child behaviour outcomes and implementation of the intervention was that the relevant families would experience problems in adapting to the adversity of stressors related to HIV and AIDS. Our purpose with this article is to highlight observations made regarding referrals of some of these problems (which could not adequately be addressed during intervention groups) from two research sites within the health and social services sector in Tshwane, Gauteng. Some women and children had problems besides HIV that required types of treatment or services that fell outside the scope of the intervention groups that they attended. It seemed significant to know when to refer and address problems outside of the research protocol (intervention) as some of the problems that these women and children experienced were extreme. The trends that were observed emerged from field notes that consisted of initial field notes, follow-up data and the observations of care workers ${ }^{1}$ and social workers. In doing so, we describe the problems experienced by participants who were in need of community-based psychosocial services. We also highlight some of the barriers that were encountered in facilitating effective referrals and remark on the lack of appropriate resources for women and children affected by HIV and AIDS.

Spencer (1993) distinguishes two distinct approaches to referrals; the interactionist approach and the structural approach. The interactionist approach tends to explain referrals in terms of referrals within a single system or organisation, but remains largely silent on the interorganisational aspects of the referral process. The structural approach on the other hand entails a systems perspective, where the role of referrals within a network of support services is examined. This article focuses on referrals within a structural approach.

\section{Background to the Kgolo Mmogo Project ${ }^{2}$}

The Kgolo Mmogo project was a five-year intervention trial that focused on developing resilience in HIV-positive mothers and their children. The study included a group-based intervention with mothers and children that followed on a comprehensive collection of data on psychological resilience factors. Follow-up psychological data collection then took place after six months, 12 months and 18 months.

The principal focus of the study was on psychological resilience in South African mothers and children who were affected by HIV and AIDS. The study was conducted by a multidisciplinary team of researchers ${ }^{3}$ from the University of Pretoria (South Africa) and Yale University, Wake Forest University and Duke University (USA). Longitudinal data were collected on resilience factors in mothers and children by using a variety of psychological assessment scales. Self-report inventories with children measured self-awareness and the ability to handle everyday pressures, anxiety, depression, coping, religious coping methods and self-concepts. Inventories with mothers measured behavioural and emotional problems in children, children's adaptive behaviours, depression, responding to negative emotions, coping strategies, religious coping methods and dysfunctional parenting. 
A theory-based psychosocial intervention was conducted with a randomly selected subgroup of the mother and child participants. The structured six-month intervention was at first conducted as weekly sessions in separate groups with the mothers and the children (14 sessions), and then conducted jointly with mothers and their children included in the same groups for the final sessions (sessions 15-24). The sessions focused on building resilience in dealing with the impact of HIV and AIDS. Themes included stress management, coping, parenting, problem solving, life skills, HIV counselling and future planning. This article reports on referrals that took place from this group intervention.

The primary aim of the overall study was to assess the effectiveness of the theory-based intervention for HIV-infected mothers and their children that was designed to improve maternal functioning and help mothers promote resilience in children at two different ages and stages of development - very young children (aged three years) and school-aged children (ages six to ten years). Intervention studies by definition usually intervene according to a stated purpose and focus - as was the case in the Kgolo Mmogo project, where a focus on intervention with women and children affected by HIV and AIDS was articulated. However, due to the focused nature of an intervention study, reliance on additional support services is often required. Similarly, in the context of a research trial study, deciding on the extent of available outside services is complex. When the focus of the intervention study involves instances of severe distress (e.g. HIV and AIDS), it can be assumed that there will be a need for a greater reliance on additional support services. This article describes the complexities that are involved in making referrals based on data gained from a research study.

\section{SYNOPSIS OF RESEARCH METHODOLOGY}

We enrolled 427 HIV-infected women and their children $(n=435)$ in a randomised controlled trial. Participants in the study were enrolled from a variety of sources (Forsyth, 2005):

- Women enrolled in a previous study, the Serithi Project (Makin, Forsyth, Visser, Sikkema, Neufeld, \& Jeffery, 2008), in which they had been followed since pregnancy. The focus of the Serithi study related to stigma and mother-to-child-transmission, however, the women did not have the opportunity to participate in a group-based intervention. The children were subsequently enrolled in the current study when they reached the age of three years. Older siblings between the ages of 6 and 10 years were also enrolled in the older children's cohort.

- Mothers with advanced HIV disease who had been referred to the Kalafong Hospital's Immunology Clinic, Gauteng province, for the initiation of ARV therapy and who had children aged between 6 and 10 .

- HIV-positive mothers with children falling in the age groups investigated in this study, who had been referred from other health clinics surrounding the Kalafong Hospital and the Mamelodi area in Tshwane.

The 436 mother-child dyads were recruited in waves of 34 and in every wave 17 mothers and their children were randomised to the experimental and control groups. The experimental group took part in the previously mentioned six months' intervention for mother and child and the control group received information on services available in the community. The intervention allowed for psychological and developmental variance in group participants. It used structured activities as a basis for exploring a variety of themes which acted as support to the mothers and their children.

The intervention was primarily intended to promote child and maternal resilience and was strongly rooted in theories of resilience (Arend, Gove, \& Stroufe, 1979; Baldwin \& Baldwin, 1990; Barnard, 1994; Bolig \& Weddle, 1988; Garmezy, 1984a, 1984b, 1991; Mallmann, 2003; Rutter, 1979, 1987, 1990, 1993; Werner \& Smith, 1982, 1992). It included site-specific intervention groups at two sites in Tshwane and home visiting for participants who were ill. Both sites were easily accessible via transport routes and were physically safe and secure. Sites consisted of large rooms with 
chairs and tables, as well as kitchen facilities, where simple meals were prepared. Separate rooms were available for smaller children and a separate intervention was developed for children under the age of three who accompanied their mothers (Duvenhage, Greyling, Finestone, \& Ferreira, 2007). Parent education was incorporated in some of the themes of the primary intervention programme. Groups were conducted by trained care workers under the supervision of qualified social workers. A paper-based manual provided assistance in terms of planning, materials per session, debriefing and goals for each session.

In this article we focus only on the data set that is based on observations we made in terms of biographic data, e.g. the field notes of social workers and care workers, and observation notes. Interventions were conducted within a wider network of health and social services. With this article, we try to highlight the intersection between intervention research and wider services that need to be accessed when participants present with severe challenges. The article describes referrals for those who were in the intervention as well as in the control group.

\section{Problem statement}

During the course of this study we became aware of inadequacies in the wider health and social sector in terms of possible resources for referrals. Some of our participants (mothers, $n=54$; children, $n=59$ ) displayed a range of psychosocial, health and other challenges and were in dire need of further support that fell outside the focus and available research protocol of the Kgolo Mmogo project. In this article we do not include cases where problems could be addressed during intervention groups, but only instances where the severity of the problem required urgent referrals. Problems relating to referral were identified in various ways. In some instances mothers, children, care workers or research assistants mentioned problems, and in other instances outcomes and responses on measures were indicative of problems. Following its identification, the extent of the problem was discussed at a meeting of relevant Kgolo Mmogo team members. In other instances a process of referral was initiated based on recommendation by the project coordinator, psychologist, social worker and research assistants. In all instances mothers were contacted for consent to continue with referral procedures. Based on the mother's consent, the social worker contacted an organisation to arrange an appointment. Mothers were provided with written details regarding the appointment. The social worker contacted both the mothers and organisations telephonically to monitor if appointments were met and (where available) what the outcome of the referral was. In 61 cases referral was successful. Of these 61 cases, 54 visited the referral institution once, and in seven cases more than once. Followup with mothers and children was complicated by issues such as changed telephone numbers and mothers not answering phone calls when the cellular phone does not indicate the identity of the caller. In 52 cases referral was unsuccessful, indicating that the mothers and children either could not be located for referral or they did not visit the referral institution.

Initial anecdotal evidence from the social workers clearly indicated the need for a database on available services that ranged from participants experiencing challenges such as depression, suicidal ideation and suspected abuse, and even neglect in some instances. More resources were aligned within the project to address the challenge of suitable referrals. For instance, some research assistants assisted the social worker with the technical aspects of the referrals and the social worker also dealt with some challenges immediately. Further support was however still needed. While a number of participants could be assisted and supported from within the intervention groups, the high frequency of referrals prompted a further analysis of the data sets. These included information about referrals within the project over a three-year period.

\section{OBSERVATIONS}

Main observations regarding data on referrals from the Kgolo Mmogo project were as follows:

- There was a noteworthy need for referrals for additional services for HIV-infected women and 
HIV-affected children attending intervention groups. This need presented in terms of severity of the problems experienced, as well as the number of participants who needed referrals.

- Available mental health and social support services in the Tshwane region of South Africa were overloaded and unable to appropriately address the needs of the population.

- Socio-economic constraints affecting this HIV-infected population could well have an impact on the effective accessing of the available support services.

In the next section we illustrate evidence for these observations by providing extracts of the stated data sets (e.g. biographical data, the field notes of social workers and care workers, and the project team's observation notes). Identifying details have been deleted from both the files and the data reflected here. Specific dates have been changed to protect the confidentiality and anonymity of participants.

\section{There was a noteworthy need for referrals for HIV-infected women and HIV-affected children attending intervention groups}

As mentioned, our data show that of the 427 mothers and 435 children enrolled for the study, 54 mothers and 59 children were in need of further referrals and presented with extreme challenges (in addition, other cases of identified problems were addressed during intervention groups). As previously stated, reasons for referral for mothers and children included psychological and behavioural issues, socio-economic concerns, partner and child abuse and neglect, and HIV-and-AIDS-specific stressors such as disclosure, grief and bereavement and pregnancy. Problems that required the referral of women related to domestic violence and relationship problems with accompanying mental health problems. For children the referrals related to behavioural problems and serious emotional difficulties, while concerns about child abuse also led to referrals.

Table 1. Reasons for referral of mothers and children

\begin{tabular}{lrlr}
\hline \multicolumn{2}{c}{ Mothers $[N=54](12.39 \%)$} & \multicolumn{2}{c}{ Children $[N=59](14.75 \%)$} \\
\hline Referral reason & Frequency & Referral reason & Frequency \\
\hline Signs of physical abuse & 12 & Behavioural problems & 22 \\
Relationship problems & 12 & Emotional problems & 18 \\
Financial insecurity & 8 & Depression & 7 \\
Depression / suicidal ideation & 8 & Suspected sexual abuse & 6 \\
Unemployment & 4 & Signs of physical and emotional abuse & 2 \\
Emotional problems & 4 & Learning problems & 2 \\
Housing problems & 3 & Health problems & 2 \\
Signs of alcohol abuse & 2 & Shelter & 2 \\
Grief and bereavement & 1 & Neglect & 1 \\
HIV and AIDS disclosure issues & 1 & & \\
\hline
\end{tabular}

In addition to the severity of problems experienced by some of the participants, $12.39 \%$ of the total number of mothers and $14.75 \%$ of the total number of child participants needed further referrals (see Table 1). The reasons for referral with the highest prevalence for mothers included suspicion of emotional and physical abuse, relationship problems, depression and suicidal ideation, and financial insecurity. Other less prevalent reasons for referral of the mothers included unemployment, emotional problems, HIV and AIDS disclosure issues, housing problems, alcohol abuse and grief and bereavement. In some instances mothers needed referrals for more than one reason.

The study revealed a slight difference in respect of the reasons for referrals of children (type of problems), but the challenges that were experienced were equally severe. Table 1 also lists the 
reasons for referral with the highest prevalence for the child participants in this study. These instances were severe and required immediate referral. As with some of the mothers, some children also needed referrals for more than one reason.

Field notes as gathered during the study provided case examples to illustrate the types and severity of problems that both mothers and children experienced and that required referral. Below we provide examples of problems related to abuse of the mother participants.

"This client indicates that her partner is verbally and physically abusive towards her. He is especially abusive to her when he is under the influence of alcohol."

"The client was raped twice. She was pregnant the second time she was raped. She says that she did not have the courage to go for counselling and that 'God will help me'."

"The client is not a group member and indicated during the interview with the Research Assistant that her partner is vulgar, very violent and beats her with irons and bottles on a regular basis. He insults her in front of other people and their child is now showing with emotional problems."

"During the interview the client indicated that the partner is very aggressive and physically abusive to the children and emotionally abusive towards herself. When the partner is around she gets very depressed and physically sick. The client indicated that there are times when she thinks of killing herself."

"The mother was threatened with a knife by her partner and is physically abused by him. That has an effect that she sometimes gets confused and loses her memory. She is afraid of [sic] her life."

The next extracts demonstrate the severity of problems related to the mental health of mothers:

"The client says that she was raped by her brother when she was eight years old. She says that she is experiencing a lot of anger and thinking of poisoning her family. Her child also shows with difficult behaviour. He takes things that do not belong to him."

“A group member took her child and left her partner because he could not pay lobola. She was previously admitted to Weskoppies psychiatric hospital because of depression. She is experiencing a lot of emotional problems because her child is still in Zimbabwe."

"The client says she feels very depressed because her disabled partner refuses that she goes to work and is emotionally abusive towards her."

The following examples reflect problems related to abuse of children:

"The mother saw her child being raped by the father. The father is currently in jail. Both the mother and child are experiencing emotional difficulties."

"The grandmother noticed that there was something wrong with her grandchild. The mother took the child to the clinic only to be told that she needs to bathe the child. The mother was not happy with this answer and took her to another clinic whereupon she was informed that her child was molested."

"During the interview the client indicated that the partner is very aggressive and physically abusive 
to the children and emotionally abusive towards herself."

The next case examples illustrate problems related to the mental health of children:

"The child is not reaching the expected developmental milestones and shows with difficulties in the school. She drew a picture depicting the genitals of herself and other members in her family."

"The child indicated during the interview with the KM research assistant that "I will slit myself with a knife when the time is right."

"During the interview with the research assistant (RA) the mother raised a concern about her child's behaviour. The child burnt her uncle's taxi and her behaviour is uncontrollable at school and at home."

"The child is showing with learning problems at school and talks of committing suicide by drowning herself."

"The child indicated on the $\mathrm{CDI}^{4}$ that she had thoughts of suicide because of her physical appearance."

"The child was involved in a car accident in 2004 and shows with scars. Physically she is experiencing a lot of pain and mentions that she thinks of committing suicide."

"The mother indicated that her child is very aggressive and violent towards people. He once took an axe at home to hit a boy who had mocked him earlier. The child told the RA that he thinks his father was poisoned by his stepmother (father died of AIDS), so that she can have his house. He told the RA that he will take his father's gun, shoot the stepmother, step on her face and take an axe to kill her. When she is dead I will drag her out of the house and take her to a dumping site or the river."

"During the interview with the RA the child indicated that the one thing that makes her sad is when she thinks of her grandfather. Upon further probing she mentioned that she was in the house when her grandmother killed her grandfather. She was present during the whole incident."

"The mother mentioned to the research assistant that the child is showing with bullying, stealing, vulgarity and aggressiveness towards other children. The child is showing furthermore with scholastic problems. The mother says that she does not have a close relationship with her child."

"The client was worried about her child's behaviours. She mentioned that her child is physically violent, verbally aggressive, vulgar and lacks concern for others as he does not apologise for hurting other people's feelings. The school is considering expelling him with immediate effect because his demerit points are now above the maximum level."

"The client indicated that she is worried about her son's future. According to her the young boy seems to be a bully towards other children, steals and has a tendency of setting fires. The boy struggled with the mother's HIV status but he also tested positive in the past year and he is not talking about his status at all." 


\section{Available health and social support services seem to be overloaded}

Our observations indicate that the available support services to which participants were referred were often overloaded. There was also a lack of capacity to deal with referrals. Field notes from the social workers indicate that support services were only able to provide limited and in many instances once-off support to the participants. In some instances, no support could be provided. Extracts from the field notes of the Kgolo Mmogo social worker serve to illustrate this point:

"Client was phoned on 27 February to arrange a home visit with a social worker as the aunt mentioned possible abuse of the child. The social worker didn't phone back with the report. On 9 March the social worker was once again contacted by the social worker at Kgolo Mmogo and the social worker reported that she didn't find them at home and wanted more information on which school the child attended. The social worker didn't come back to us and she was phoned on 12 March. She was not in office and no information was available."

"The child is showing with emotional problems and needs urgent therapy sessions. No therapist available to see the child in Mamelodi. The possibility exists to see a therapist in town, but transport is indicated as problematic."

"The child was referred in January and again in March. The child showed neglect and he seldom attended school. The child's teacher also complained about his poor scholastic performance. Promises were made to visit the family, but this family could not be traced according to the social worker at a social service agency. During the child's 18 month interview at Kgolo Mmogo the child mentioned that he thinks of killing himself, that he didn't have friends and that he was hungry. The family received food parcels from Kgolo Mmogo and was once again urgently referred. Several social service agencies were phoned as this family stays in a community where there are no social workers available. An auxiliary social worker was assigned to visit this family but we are still awaiting feedback."

"The client is being abused by her partner and fears for her life. She asked for a referral for a place of safety. She was referred to a social service agency on 18 May but the social worker told her to go to court and take the matter further. On 26 May the mother got a referral to go to Cullinan Court."

"The mother complained on 20 April during the interview with the research assistant about her child's hyperactivity and learning problems. The social service agency contacted could not help and they referred to a different agency on 11 May. This agency referred once again to another agency on 24 May but was also unable to help the child."

"The mother and child were referred for depression and financial support. The social support agency they have been referred to could not help them and referred them to a different agency. This agency doesn't offer a service to support children and is only able to provide help for adults experiencing mental health problems."

"The child's cousin was getting ready to bathe her when she realised that the child's underwear was bloodied. When asked what happened, she did not and could not say. Then the father hit the child insisting that she should say who did it. The mother took the child to the clinic but was told that she has to take her to the police first. At the police station she was showed away because the surgeon was apparently in a meeting and got told to go home. Later she was examined and the molestation confirmed. The child did not receive any counselling and now shows with aggressive behaviour. The 
mother asks for an urgent referral."

Some of the indications of overload and lack of capacity to deal with referrals are based on personal follow-up by the Kgolo Mmogo social worker via telephone conversations with various agencies. Other indications are secondary reports from the participants who reported that they were not assisted or only assisted sparsely. Nevertheless, the severity of the initial reasons for referral and the lack of capacity for participants to be assisted are disquieting.

\section{Individual and systemic causes have an impact on the effective accessing of available support services}

In many instances follow-up notes on referrals indicated that participants were unable to act on referrals due to financial and socio-economic constraints on their side. Mothers indicated that they did not have sufficient financial resources for transport costs or that they were experiencing too many other problems which prevented them from acting on the referrals. Some extracts from our field notes illustrate this situation:

"The mother and child showed with suicidal ideation and were referred for therapy on 6 November. The client didn't turn up to collect her referral saying that she was experiencing a lot of family problems. The client was phoned several times thereafter but her cell phone was not working. On 10 November a research assistant of KM went to check on her. The client mentioned that she would not be able to attend the therapy sessions and didn't want to take it any further. In January the client was once again referred after she had asked for another referral. On 2 February the care workers did a home visit to her house as she was selected for the group but did not turn up for the group. The client mentioned that she was having financial difficulties and relationship problems and wouldn't be able to attend the groups."

"The child is referred but we cannot get hold of the mother. The mother was very anxious to get help for her child. The mother's cell phone is giving a 'not available' message and the referral will have to wait until the mother fetches it at KM."

"The mother indicated that she was worried about her child's behaviour problems. The child was referred on 10 November, but the mother could not take him because of transport problems. The mother asked for another referral for help with financial problems on 26 April. The mother did not reply on the follow-up calls on the 10,12 and 21 May. Her cell phone was not working. The child mentioned during the interviews on 4 June that he is thinking about committing suicide. The research assistant explained the urgency of the situation to the mother and a third referral was given to the mother. The child and mother attended one session according to the social worker."

"The client told the research assistant that she was abused by her partner and asked for a referral letter on 26 August. She didn't have any contact number. The client didn't collect her referral letter."

"On 19 April the mother mentioned that she was worried about her son's behaviour problems. He is showing aggressive behaviour towards her, he burnt his sneakers and he plays with matches. The mother is also afraid of her husband that is extremely jealous. The mother and child were referred but didn't go to the referral agency. The mother returned on 10 May and said that they have 'too many problems' and can't afford transport."

"The client indicated that she feared death and that she was depressed. The client could not be 
referred as she had no contact number and therefore she could not be reached to give her a referral letter."

Data from our study therefore confirm findings by Carlson and Goetz (2000), namely, that limited patient funds can be an impediment to effective referrals. However, it may also be that the reasons for non-follow-up on referrals by our participants do not relate to financial or socioeconomic constraints alone. Participants probably indicated financial constraints, when a number of other reasons underlay the real motivation for not acting on referrals. The severity of problems experienced, the debilitating effects of depression, possible fears about loss of parental care and supervision rights, or uncertainty regarding the social system could all have been factors causing a lack of follow-up on referrals. Based on the data we have available, though, the primary reasons stated by our participants relate to financial and socio-economic constraints. These constraints impact both on their ability to access services, as well as on their own contactability - when they cannot be reached on their cell phones, this is most likely due to the fact that the services have been suspended because of lack of funds.

\section{RECOMMENDATIONS}

Based on the observations and field notes from this study, the following recommendations can be made regarding some strategies that could be introduced within the intervention group in order to enhance the efficacy of the referral process.

\section{Include a team member in the intervention study who is specifically tasked with follow-up on referrals}

Within the Kgolo Mmogo project, one social worker was tasked to follow up on all referrals given to participants after initial induction into the project. This included participants who were not involved in the group intervention. The following field notes from the social worker indicate that further contact with the mother participants was often needed in order to ensure successful followthrough on referrals:

"Therapy was arranged for this child. This child and mother could not be traced on their available cell phone numbers. The mother was phoned on 20, 23, 24 and 26 January and on 18 February different times during the day and after-hours, but the phone kept on switching to voice mail. The mother has not returned any of the phone calls or made any missed calls to our number. The mother could only be reached later on during the follow-up interview to make another referral."

"The client's aunt indicated that the client was bedridden and needed assistance with applying for a grant on 17 February. The aunt fetched the referral and food parcel on 18 February at Kgolo Mmogo. The client did not make use of the referral and she was phoned several times on 10, 15, 23 February and on 10 March at home. Her phone at home was not answered on any of the occasions she was phoned and she didn't own a cell phone. The client was traced on 23 February to follow up on her referral."

"During the baseline interview on 26 August the mother indicated that her child was aggressive and asked for a referral. The mother said she would take the child on 6 September, but she failed to do so. She was phoned on 20 September to follow up on her referral, but could not be reached. On the 27 September it was only possible to leave her a voice message on her cell phone. The client was contacted on 4 October and another appointment was scheduled."

"The child was hit by a car and he was referred on 17 March. The mother didn't take the child for 
therapy and mentioned that she was too sick to take him. She was phoned on 2 May and promised to take her child for therapy the following day, but she didn't take him. She only took her child on 10 May to the Kgolo Mmogo social worker."

"The client showed with emotional difficulties after the death of her uncle and was referred on 23 August. The client was ill and could not go for therapy. She was phoned several times and was only able to see the social worker on 1 October."

The complexity of the referral process within a research project that included intervention caused a significant additional workload for the project social worker in terms of monitoring and follow-up. However, within the study's protocol, such referrals were viewed as central to the support provided to the mothers and children affected by HIV and AIDS.

\section{Optimise in-group support and provide functional advice on effective access of support services within groups}

Our data indicate that a number of the participants could be supported effectively within the groups. It also seems that in-group support and sharing of information provided the participants in the study with functional advice on ways in which to access wider support resources more effectively. Field notes from the social worker indicated positive processes within the groups.

Figure 1 indicates the number of mother participants who were supported within the group. It appears that relationship problems, HIV and AIDS disclosure and support for grief and bereavement were particularly suitable matters to be addressed within the groups. Some grief and bereavement issues only became apparent after a more trusting relationship had been established with participants.

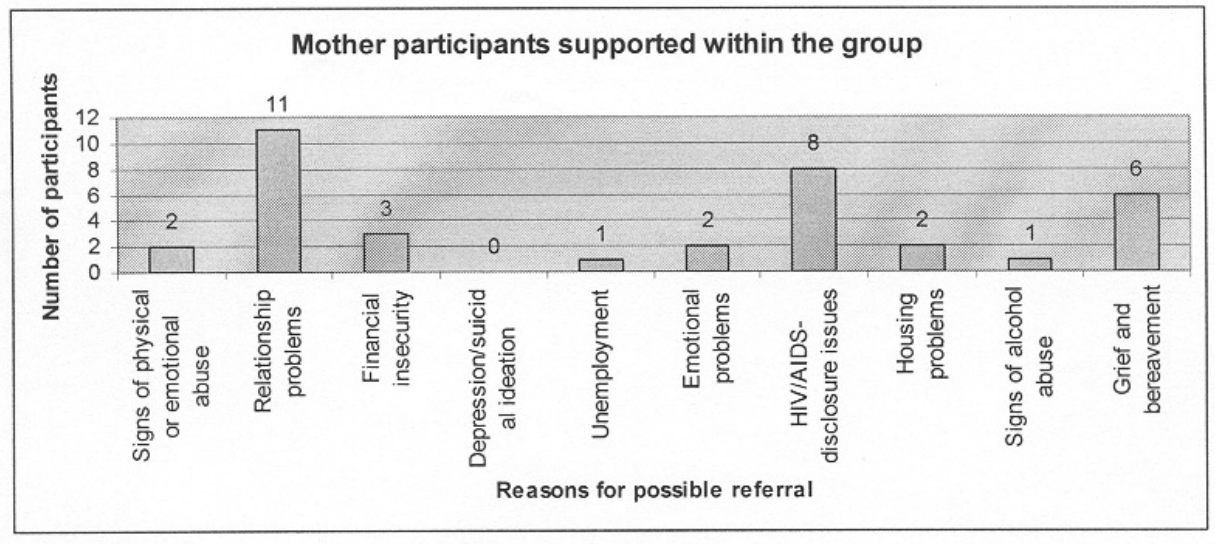

Figure 1. Number of mother participants supported within the group

Field notes from the social worker also indicate that some mothers benefited from sharing their stories:

"The client told the group that she stole money and slept around when she was younger. She feels very guilty about her behaviour. The group inspired her to forgive herself and to take care of her children." 
“A group member told the rest of the group you don't know what you're talking about. She told the group that she was very angry about her status and that she showed physical aggressiveness towards her child. She also told the group that she was raped and then got pregnant. The group supported this mother and gave her an opportunity to talk about her feelings. The client indicated after the sessions that she felt better about herself and less depressed. She also indicated that she learnt in the group how to communicate with her child and how to discipline her child without physically harming her."

"The client lives under very poor circumstances. Her child of 8 years old shows with a low esteem and is sickly. She didn't want to expose her child to school and her child had never attended school. The client's mother chased her away and her partner left her. The group brought clothes and food to help the family. The group also encouraged the mother to take her child to school which she did. The mother didn't need a referral and is looking for work at this stage."

"The client got pregnant and found out about her HIV status during her pregnancy. She didn't know how to tell her husband about her HIV-positive status. The group members brought baby clothes and supported her in how to disclose to her husband."

"The client is waiting for a hip replacement and has difficulty walking. The group members helped her during the sessions where there were physical activities involved. They also helped her with her son. She was an inspiration to the rest of the group, because despite her physical disability she had a positive attitude throughout the intervention."

"The client has relationship problems and didn't know how to disclose her positive HIV status to her partner. The group supported her by telling her how they dealt with disclosing to their partners. They encouraged her to think of herself and her children's future."

For the child participants in the study, it seemed that support within the group proved to some extent suitable in terms of behaviour problems. While these apparent improvements are still to be proved conclusively at the end of the study (based on all follow-up data), initial reports indicate some observed improvements. Three child participants also benefited from in-group support for suspected sexual abuse, disclosure of HIV status and health problems respectively. In the case of suspected sexual abuse, the mother was advised within the group on ways in which to explore her suspicions. Her further investigation eventually resulted in her suspicions being proved wrong. The status disclosure issues of another participant were supported effectively within the group. Where the child was experiencing health problems, a mother-child dyad was supported equally effectively within the group in terms of ways of dealing with the health problems. The issues for which child participants received support (either for themselves or their mothers) within the group to deal with the initial reasons for referral were as follows: One child received help for sexual abuse, one for disclosure of HIV status, one for health problems and seven for behaviour problems.

\section{CONCLUSION}

This article aims at describing the complexities that were involved in making referrals from a research project based on intervention groups for mothers and children affected by HIV and AIDS. While intervention groups were certainly helpful in addressing a large proportion of difficulties faced by women who were HIV infected and their children, such interventions were insufficient for addressing all problems. Referral of some problems (e.g. relationship problems) could be delayed to establish whether a participant could be helped during the intervention group. However, other problems (e.g. child abuse, suicidal ideation) necessitated more urgent referral to appropriate services. There was a significant need for referrals of HIV and AIDS-infected women and children in the interven- 
tion groups due to the severity of the problems experienced and the large number of participants who needed referrals. From our observations it is however clear that available health and social support services in the Tshwane region of South Africa are overloaded and that the socio-economic constraints suffered by participants in intervention groups have an impact on their effective accessing of the available support services. These observations may inform the future planning of intervention studies in social contexts of economic constraint.

\section{NOTES}

1. In this study 'care workers' refer to women who were recruited to the project from the community in which it was conducted. The care workers were responsible for facilitating the mother and child groups by means of a theory-based manual that described every session.

2. The Kgolo Mmogo project was funded by the National Institutes of Health (NIH), NIMH grant R01 MH076442-01. ("Kgolo Mmogo" means "growing together".)

3. Principal investigators: Brian Forsyth (Yale University) and Irma Eloff (University of Pretoria). The project team consisted of Michelle Finestone, Jenny Makin, Liesel Ebersöhn, Ronél Ferreira, Maretha Visser (University of Pretoria), Alex Boeving (Wake Forest University), Kathleen Sikkema (Duke University) and Margaret Briggs-Gowan (Yale University).

4. Child Depression Inventory.

\section{REFERENCES}

Arend, R., Gove, F. L., \& Stroufe, A. (1979). Continuity of individual adaptation from infancy to kindergarten: A predictive study of ego-resiliency and curiosity in preschoolers. Child Development, 50, 950-959.

Baldwin, A. L., Baldwin, C., et al. (1990). Stress-resistant families and stress-resistant children. In J. Rolf, A. S. Masten, D. Cicchetti, K. H. Nuechterlein, \& S. Weintraub (Eds), Risk and protective factors in the development of psychopathology, pp. 257-280. New York: Cambridge University Press.

Barnard, C. P. (1994). Resiliency: A shift in our perception? The American Journal of Family Therapy, 22, 135-144.

Bolig, R., \& Weddle, K. D. (1988). Resiliency and hospitalisation of children. Children's Health Care, 16, 255-260.

Carlson, J., \& Goetz, R. (2000). Referrals to Private Practice Mental Health Occupational Therapy. Occupational Therapy in Mental Health, 15, 61-75.

Castro-Leal, F., Dayton, J., Demery, L., \& Mehra, K. (2000). Public spending of health care in Africa: Do the poor benefit? Bulletin of the World Health Organization, 78, 66-78.

Covell, N. H., Essock, S. M., Felton, C., \& Donahue, S. A. (2006). Characteristics of Project Liberty clients that predicted referrals to intensive. Mental Health Services, 9, 1313-1315.

Duvenhage, M., Greyling, S., Finestone, M., \& Ferreira, R. (2007). Kgolo Mmogo: Intervention sessions for 3-5 year-old children. Unpublished manual developed for the Kgolo Mmogo project.

Forsyth, B. (2005). Promoting resilience in young children of HIV-infected mothers in South Africa. Research proposal submitted to the National Institutes of Health, April 2005.

Garmezy, N. (1984a). Stress resistant children: The search for protective factors. In: J. F. Stevenson (Ed.), Recent research in developmental psychopathology. Journal of Child Psychology and Psychiatry book supplement, 4, pp. 213-232, Oxford: UK Pergamom.

Garmezy, N. (1984b). Project competence: The Minnesota studies of children vulnerability to psychopathology. In N. Watt, E. J. Antony, L. C. Wynne, \& J. E. Rolf (Eds), Child at risk for schizophrenia, pp. 289-309. Cambridge: UK: University Press.

Garmezy, N. (1991). Resiliency and vulnerability to adverse developmental outcomes associated with poverty. American Behavioral Scientist 34, 416-430.

Gwatkin, D. R., Bhuiya, A., \& Victora, C. (2004). Making health systems more equitable. The lancet.com, 364, 1273-1280.

Mallmann, S. (2003). Building resilience in children affected by HIV/AIDS. Cape Town: Maskew Miller.

Makin, J. D., Forsyth, B. W. C., Visser, M. J., Sikkema, K. J., Neufeld, S., \& Jeffery, B. (2008). Factors affecting disclosure in South African HIV-positive pregnant women. AIDS Patient Care and STDs, 22, 907-916. 
Makinen, M., Waters, H., Rauch, M., Almagambetova, N., Bitran, R., Gilson, L., McIntyre, D., Pannarunothai, S., Prieto, A. L., Ubilla, G., \& Ram, S. (2000). Inequalities in health care use and expenditures: empirical data from eight developing countries and countries in transition. Bulletin of the World Health Organization, 78, 55-65.

Maniadaki, K., Sonuga-Barke, E., \& Kakouros, E. (2006). Adults( self-efficacy beliefs and referral attitudes for boys and girls with AD/HD. European Child and Adolescent Psychiatry, 15, 132-140.

Rutter, M. (1979). Protective factors in children(s responses to stress and disadvantage. In: I. A. Hersov, \& D. Shaffer (Eds), Aggression and antisocial behaviour in childhood and adolescence, pp. 95-113. Oxford: UK Pergamom.

Rutter, M. (1987). Psychosocial resilience and protective measures. American Journal of Orthopsychia, 57 , 316-331.

Rutter, M. (1990). Psychosocial resilience and protective mechanisms. In J. Rolf, A. S. Masten, D. Chicchetti, K. H. Nuechterlein, \& S. Weintraub (Eds), Risk and protective factors in the development of psychopathology: Vol III: Social competence in children, pp. 49-74. Hanover, NH: University Press in New England.

Rutter, M. (1993). Resilience: Some conceptual considerations. Journal of Adolescent Health, 14, 626-631.

Spencer, J. W. (1993). Making 'Suitable Referrals': Social workers' construction and use of informal referral networks. Sociological Perspectives, 36, 271-285.

Werner, E. E., \& Smith, R. S. (1982). Vulnerable but invincible: A longitudinal study of resilient children and youth. New York: McGraw-Hill.

Werner, E. E., \& Smith, R. S. (1992). Overcoming the odds: High risk children from birth to adulthood. Ithaca, NY: Cornell University Press. 